\title{
Solution SAXS measurements over a wide temperature range to determine the unperturbed chain dimensions of polystyrene and a cyclic amylose derivative
}

\author{
Ken Terao, Naoya Morihana and Hiromi Ichikawa
}

The mean-square radii of gyration $<S^{2}>$ of two polystyrene (PS) samples with weight-average molar masses $M_{\mathrm{w}}$ of $2.18 \times 10^{4}$ and $3.88 \times 10^{4}$ in toluene and 2-butanone and of a cyclic amylose tris(phenylcarbamate) (cATPC) with a $M_{\mathrm{w}}$ of $4.73 \times 10^{4}$ in tetrahydrofuran were determined by synchrotron radiation small-angle X-ray scattering measurements over a wide range of temperatures from $-77^{\circ} \mathrm{C}$ to $70^{\circ} \mathrm{C}$. Both PS and cATPC are sufficiently soluble to enable SAXS measurements even at $-77^{\circ} \mathrm{C}$ in the solvents used. The $\left\langle S^{2}>\right.$ of CATPC does not depend on temperature over the range investigated here. This result may be reasonable for such rigid ring polymers. In contrast, the radii of PS depend on temperature to a significant degree, whereas the second virial coefficient is mostly temperature independent. The resulting characteristic ratio $\boldsymbol{C}_{\infty}$ for PS in toluene decreases monotonically with increasing temperature, as predicted both by the rotational isomeric state (RIS) and by (helical) wormlike chain models. However, $\boldsymbol{C}_{\infty}$ in 2-butanone exhibits a minimum $\sim 10^{\circ} \mathrm{C}$ and increases with increasing temperature, suggesting that the RIS energy parameters should be affected by the intermolecular interactions between the polymer and solvent.

Polymer Journal (2014) 46, 155-159; doi:10.1038/pj.2013.76; published online 11 September 2013

Keywords: amylose derivative; characteristic ratio; low temperature; polystyrene; radius of gyration; small-angle X-ray scattering

\section{INTRODUCTION}

The unperturbed dimensions of polymers in solution are discussed in terms of the rotational isomeric state (RIS) model $^{1}$ and/ or the (helical) wormlike chain model. ${ }^{2-4}$ Both models predict that the unperturbed dimensions depend on temperature. The chain dimensions were observed to depend on temperature for some flexible polymers, for example, polystyrene (PS), ${ }^{5,6}$ poly $(\alpha$-methylstyrene $),{ }^{6,7} \quad 1,4$-polybutadiene ${ }^{7}$ and syndiotactic poly(methylmethacrylate $)^{8}$ from near room temperature to $\sim 60^{\circ} \mathrm{C}$. Other than this temperature range, Hong et al. ${ }^{9}$ measured light scattering for PS up to $140{ }^{\circ} \mathrm{C}$ to investigate excluded-volume effects. Furthermore, the intrinsic viscosities of poly $(n$-hexylisocyanate $),{ }^{10}$ polydialkylsilanes, ${ }^{11,12}$ polyfluorene ${ }^{13}$ and cellulose tris(phenylcarbamate) ${ }^{14}$ were also determined at various temperatures to determine the variation in chain stiffness with temperature, which is directly related to the unperturbed chain dimensions, but $-27^{\circ} \mathrm{C}$ was the lowest temperature studied here. Although this temperature is still much higher than the melting points for some major organic solvents, that is, $\sim-100^{\circ} \mathrm{C}$, several scattering experiments have been conducted at lower temperatures such as PS in carbon disulfide ${ }^{15-17}$ and cellulose triacetate in methyl acetate ${ }^{18}$ to investigate gel formation. Determining the polymer dimensions in solution over a wider range of temperature between the melting and boiling points should be helpful in understanding the temperature-dependent conformation of polymer chains in more detail. However, conventional static light scattering methods cannot be used at low temperatures due to water condensation because most light scattering instruments have large thermostated baths with refractive index matching media, such as toluene, xylene and specific silicone oils, to avoid stray light. A thin capillary tube can be used for small-angle X-ray scattering ${ }^{19}$ because the refractive indices of quartz and organic solvents are substantially close to unity.

Therefore, we performed synchrotron radiation small-angle X-ray scattering (SAXS) measurements of PS in toluene and in 2-butanone (MEK) at temperatures between $-77^{\circ} \mathrm{C}$ and $70{ }^{\circ} \mathrm{C}$ to investigate the temperature coefficient of unperturbed chain dimensions. The recently investigated cyclic amylose tris(phenylcarbamate) $(\text { ATPC) })^{20}$ that acts as rigid ring in solution was also measured in tetrahydrofuran (THF) to test the apparatus. As mentioned in our recent paper, cATPC50K has substantially the same $\left\langle S^{2}\right\rangle_{z}$ as the rigid ring limit. ${ }^{20}$ Thus, the dimensional properties of cATPC50K 
should not exhibit any temperature dependence in THF. Note that all three systems are good solvents near room temperature. ${ }^{6,20,21}$

\section{EXPERIMENTAL PROCEDURE}

\section{Samples and solvents}

The two previously investigated linear PS samples PS22K and PS39K were used in this study. ${ }^{22}$ These samples were synthesized as precursors of the 4 -arm star PS samples $4 \mathrm{~S} 22$ and $4 \mathrm{~S} 39$ by living anionic polymerization. The weightaverage molar masses $M_{\mathrm{W}}$ were determined by static light scattering in benzene at $25^{\circ} \mathrm{C}$ to be $2.18 \times 10^{4}$ and $3.88 \times 10^{4}$ for PS22K and PS39K, respectively, and the ratio of $M_{\mathrm{w}}$ to the number-average molar mass $M_{\mathrm{n}}$ was determined by size exclusion chromatography to be 1.02 for both samples. ${ }^{22} \mathrm{~A}$ cyclic amylose tris(phenylcarbamate) sample, cATPC50K, ${ }^{20}$ with an $M_{\mathrm{w}}$ of $4.73 \times 10^{4}$ was also used in this study. The three organic solvents, toluene, MEK and THF, were purified by fractional distillation over $\mathrm{CaH}_{2}$.

\section{Small-angle X-ray scattering (SAXS) measurements}

SAXS measurements at low temperatures between $-80^{\circ} \mathrm{C}$ and $40^{\circ} \mathrm{C}$ were made at the BL40B2 beamline in SPring-8 (Hyogo, Japan) with a specially designed $2 \mathrm{~mm} \phi$ capillary cell (Figure 1 ) with a thermostated nitrogen jet (Cryojet, Oxford Instruments, Abingdon, Oxon, UK). The flow rate of $\mathrm{N}_{2}$ gas was set to be $8000 \mathrm{ml} \mathrm{min}^{-1}$ for the sample flow and $6000 \mathrm{ml} \mathrm{min}^{-1}$ for the shield flow. The distance between the capillary cell and the head of the Cryojet was set to $\sim 4 \mathrm{~mm}$. The wavelength, camera length and accumulation time were chosen as $0.1 \mathrm{~nm}, 4000 \mathrm{~mm}$ and $120 \mathrm{~s}$, respectively. The temperature of the $\mathrm{N}_{2}$ gas at the capillary was substantially the same as the set temperature above $-50^{\circ} \mathrm{C}$, but it was $\sim 3^{\circ} \mathrm{C}$ higher at $-80^{\circ} \mathrm{C}$. Thus, we consider the temperature in the cell to be $-77^{\circ} \mathrm{C}$ when the temperature was set to $-80^{\circ} \mathrm{C}$. We were not able to directly determine the temperature in the scattering volume, but the temperature should be substantially close to the $\mathrm{N}_{2}$ gas temperature because the values of the excess scattering intensity divided by the polymer mass concentration $\Delta I(q) / c$ at a wide angle were substantially independent of the concentration, although the scattering intensity of the solvent depended to a significant degree on the temperature. The scattering intensities at high temperatures between $15{ }^{\circ} \mathrm{C}$ and $70{ }^{\circ} \mathrm{C}$ were acquired at the BL-10C beamline at KEK-PF (Ibaraki, Japan) using a $0.15 \mathrm{~nm}$ wavelength with the cell holder thermostated by the circulating water bath. A camera length of $2000 \mathrm{~mm}$ and an accumulation time of $300 \mathrm{~s}$ were chosen for this study. The light scattered from the two X-ray sources was detected using a Rigaku R-AXIS VII imaging plate. The magnitude of the scattering vector $q$ at each pixel on the imaging plate was determined based on the diffraction from silver behenate and/or lead stearate. The scattering intensity $I(q)$ at each $q$ was obtained from the circular average method and was corrected for the incident-beam intensity and the transmittance, both of which were determined using the ionic chambers installed at the upper and lower ends of the cell. The intensity $I(q)$ of the solvent was subtracted from that of the solution in the same capillary to determine the excess scattering intensity $\Delta I(q)$. Four solutions with different polymer mass concentrations $c$ were used to extrapolate $(c / \Delta I(q))^{1 / 2}$ to infinite dilution. The Berry square root plot and the Guinier plot were used to analyze the data for PS and cATPC, respectively, to determine the $z$-average mean-square radius of gyration $\left\langle S^{2}\right\rangle_{\mathrm{z}}$, the particle scattering function $P(q)$ and the second virial coefficient $A_{2}$, respectively, because the former plot is suitable to analyze linear flexible chains ${ }^{23,24}$ and the latter is suitable for rigid ring polymers. ${ }^{20,25}$ Figure 2 shows the Berry plots for PS22K and PS39K in toluene at $-77^{\circ} \mathrm{C}$. This figure indicates sufficient accuracy to determine $\left\langle S^{2}\right\rangle_{\mathrm{z}}$ and $A_{2}$, even at low temperature. Note that the optical constant $K$, including the instrument constant, was determined to obtain $A_{2}$ from $M_{\mathrm{w}}$ and the reduced intensity $(\Delta I(0) / c)_{c=0}$ at $c=0$ and $q=0$ by the relation $K[c / \Delta I(0)]_{c=0}=M_{\mathrm{w}}{ }^{-1}$

\section{RESULTS AND DISCUSSION}

Temperature independent chain dimensions of cATPC in THF Figure 3 displays the Guinier plots $\left[\ln P(q)\right.$ versus $\left.q^{2}\right]$ for cATPC in THF at $60^{\circ} \mathrm{C}, 45^{\circ} \mathrm{C}, 25^{\circ} \mathrm{C},-45^{\circ} \mathrm{C}$ and $-77^{\circ} \mathrm{C}$. The data points at all temperatures investigated here can be fitted by a universal line. The common value of $\left\langle S^{2}\right\rangle_{\mathrm{z}}{ }^{1 / 2}$ was determined from the initial tangent to be $4.9 \mathrm{~nm}$, which is substantially the same as the literature value $(5.1 \mathrm{~nm})$ in 1,4 -dioxane at $25^{\circ} \mathrm{C} .{ }^{20}$ Thus, the current cell system may be suitable to investigate the dimensional properties of the polymer in solution over a wide range of temperature. Another point is that the rigid ring amylose derivative cATPC exhibits good solubility in THF, even at $-77^{\circ} \mathrm{C}$.

\section{Temperature-dependent chain dimensions of PS in toluene and MEK}

The experimental results of $\left\langle S^{2}\right\rangle_{\mathrm{z}}$ in toluene and MEK at various temperatures are presented in Table 1, and the temperature dependences of $\left\langle S^{2}\right\rangle_{\mathrm{z}}$ for the two PS samples in toluene and MEK are presented in Figure 4a. Note that the data obtained in toluene at $15^{\circ} \mathrm{C}$ are fitted well by the $\left\langle S^{2}\right\rangle_{\mathrm{z}}-M_{\mathrm{W}}$ relationship reported by Abe et al. ${ }^{26}$ (not shown here). Interestingly, the data in MEK do not depend significantly on temperature, with $\left\langle S^{2}\right\rangle_{\mathrm{z}}$ exhibiting little change at $-40^{\circ} \mathrm{C}$ and $70^{\circ} \mathrm{C}$. The Holtzer plots of the MEK data at the two temperatures are almost the same as shown in Figure 5, indicating highly similar chain conformations at the two temperatures.

Conversely, the $\left\langle S^{2}\right\rangle_{\mathrm{z}}$ are systematically larger in toluene than in MEK. This difference is likely due to the intramolecular excludedvolume effect because the $A_{2}$ in toluene is significantly larger than that in MEK. ${ }^{27}$ Indeed, the current $A_{2}$ data for the two PS samples in toluene are approximately three times larger than those in MEK (see Figure $4 \mathrm{~b})$. Note that these $A_{2}$ values are close to the literature values determined by static light scattering near room temperature. ${ }^{27,28}$ While Akcasu and $\operatorname{Han}^{29}$ predicted the $\Theta$ temperature in toluene to be $-41^{\circ} \mathrm{C}$ using an expansion factor of $12^{\circ} \mathrm{C}$, the current $A_{2}$ data are almost temperature independent, indicating that toluene and MEK are good and intermediate solvents, respectively, even at $-77^{\circ} \mathrm{C}$. Thus, we may expect the temperature dependence of the radius expansion factor $\alpha_{\mathrm{S}}^{2}$, which is defined as the ratio $\left.\left\langle S^{2}\right\rangle /<S^{2}\right\rangle_{0}$ of

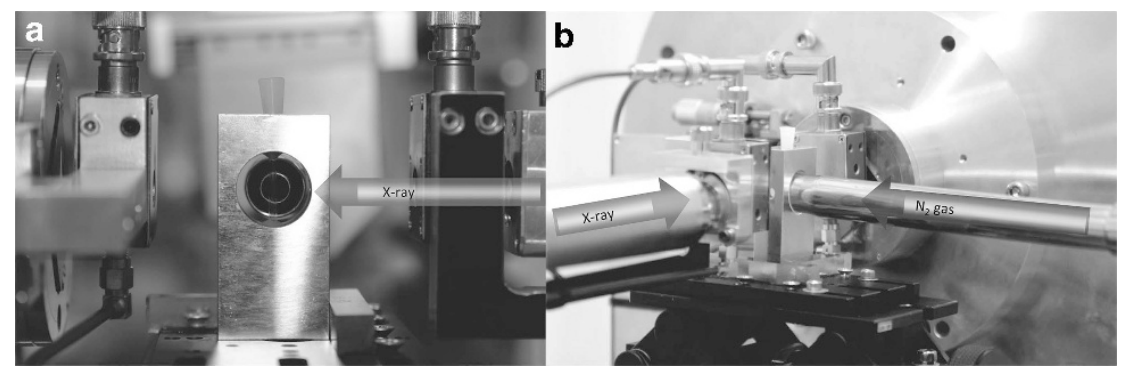

Figure 1 A SAXS cell for low temperature measurements. (a) Front view. (b) Oblique view. A full color version of this figure is available at Polymer Journal online. 


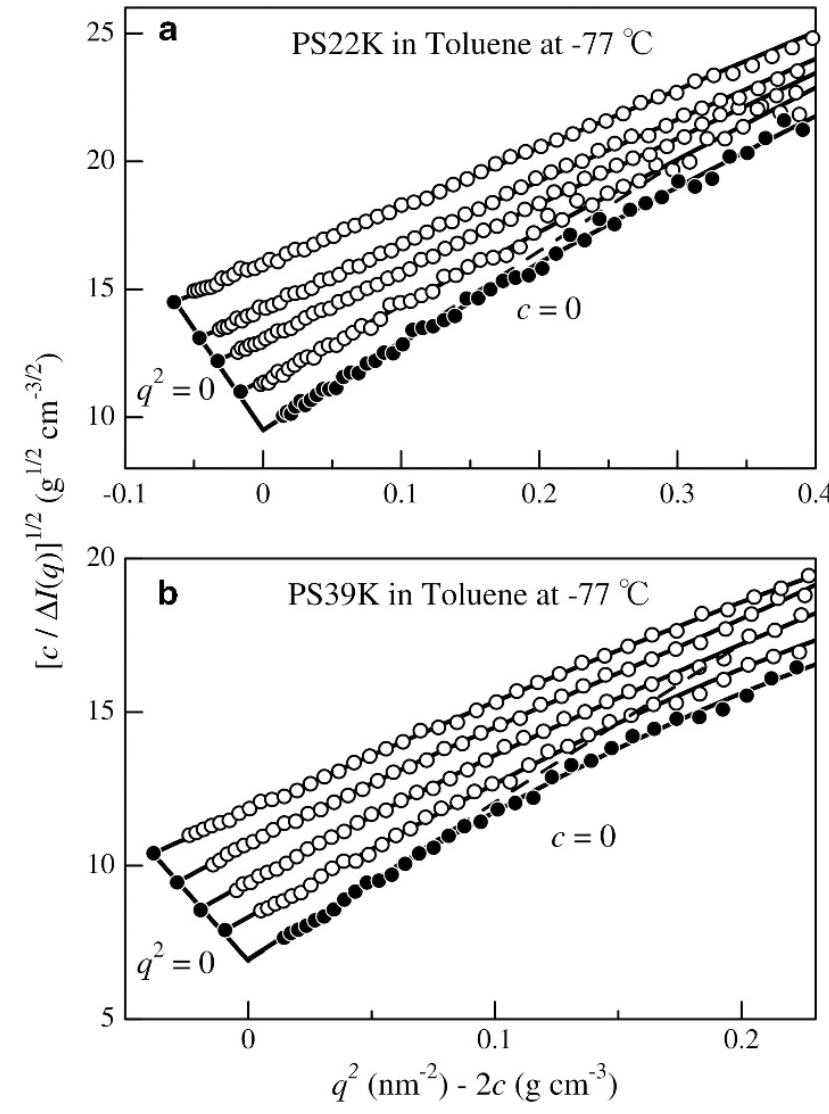

Figure 2 Two examples of SAXS data at low temperature. Berry plots for PS22K (a) and PS39K (b) in toluene at $-77^{\circ} \mathrm{C}$. Unfilled and filled circles denote the experimental data and the extrapolated values to $c=0$ or $q^{2}=0$, respectively. Broken lines indicate the initial slopes.

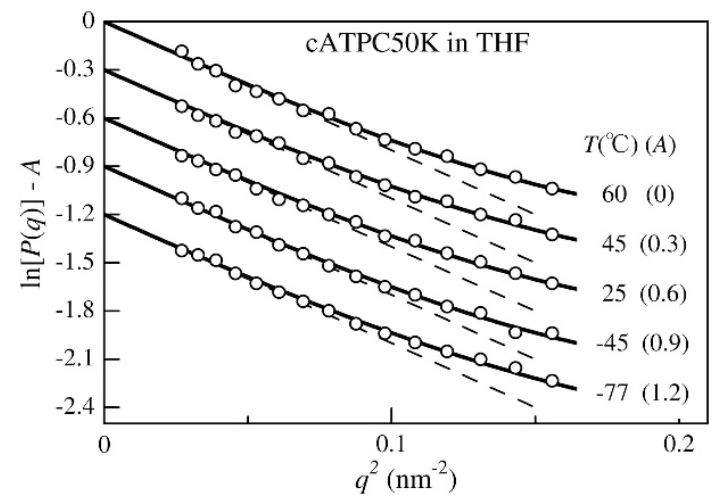

Figure 3 Guinier plots for CATPC50K in THF at the indicated temperatures. Broken lines indicate the initial slopes. The ordinate values are shifted by $A$ for clarity.

the perturbed to unperturbed radii of gyration, to be negligibly small. Therefore, we estimated $\alpha_{\mathrm{s}}^{2}$ in toluene to be 1.28 and 1.40 for PS22K and PS39K, respectively, based on the literature $\alpha_{s}^{2}$ values in toluene of $15^{\circ} \mathrm{C} .{ }^{26}$ Conversely, $\alpha_{\mathrm{s}}{ }^{2}$ in MEK was estimated to be 1.04 and 1.08 for PS22K and PS39K, respectively. These values were determined from the viscosity expansion factor $\alpha_{\eta}^{3}$ in MEK at $35^{\circ} \mathrm{C}^{21}$ because $\alpha_{s}^{2}$ values are not available for low molar mass PS samples in MEK, and $\alpha_{s}^{2}$ is mostly the same as $\alpha_{\eta}^{3}$ when $\alpha_{\eta}^{3}<1.1$ according to the quasi-
Table 1 Mean-square radius of gyration $\left\langle S^{2}\right\rangle_{z}$ for the polystyrene (PS) samples in toluene and MEK

\begin{tabular}{|c|c|c|c|}
\hline \multirow[b]{2}{*}{ Solvent } & \multirow[b]{2}{*}{$T\left({ }^{\circ} \mathrm{C}\right)$} & \multicolumn{2}{|c|}{$<S^{2}>_{z}\left(n m^{2}\right)$} \\
\hline & & PS39K $M_{w}=3.88 \times 10^{4}$ & $P S 22 K M_{w}=2.18 \times 10^{4}$ \\
\hline \multirow[t]{8}{*}{ Toluene } & -77 & 43.5 & 21.5 \\
\hline & -40 & 41.0 & 20.0 \\
\hline & 0 & 38.5 & 20.0 \\
\hline & 15 & 39.0 & 19.5 \\
\hline & 30 & 38.5 & 19.0 \\
\hline & 40 & 38.0 & 19.8 \\
\hline & 45 & 38.5 & 18.8 \\
\hline & 70 & 37.0 & 18.8 \\
\hline \multirow[t]{8}{*}{ MEK } & -77 & 31.5 & 16.8 \\
\hline & -40 & 30.5 & 15.8 \\
\hline & 0 & 29.0 & 15.2 \\
\hline & 15 & 28.0 & 15.0 \\
\hline & 30 & 29.0 & 15.5 \\
\hline & 40 & 29.0 & 15.5 \\
\hline & 45 & 29.5 & 15.6 \\
\hline & 70 & 30.5 & 16.2 \\
\hline
\end{tabular}

two-parameter theory, ${ }^{3,30,31}$ with the Domb-Barrett function ${ }^{32}$ used to determine $\alpha_{s}{ }^{2}$ and the Barrett function ${ }^{33}$ used to determine $\alpha_{\eta}{ }^{3}$.

The characteristic ratio $C_{\infty}$ can be defined as $\left(<R^{2}>_{0} / n b^{2}\right)_{n \rightarrow \infty}$ or $\left(6<S^{2}>_{0} / n b^{2}\right)_{n \rightarrow \infty}$ where $n, b$ and $<R^{2}>_{0}$ denote the number of $\mathrm{C}-\mathrm{C}$ bonds in the main chain, the bond length $(0.154 \mathrm{~nm})$ and the unperturbed mean-square end-to-end distance, respectively. Although the two current samples may not have a sufficiently high molar mass to directly obtain $C_{\infty}$, we estimated this value in terms of the wormlike chain model, in which $\left\langle S^{2}\right\rangle_{0}$ can be expressed as the formula ${ }^{34}$

$$
\left\langle S^{2}\right\rangle_{0}=\lambda^{-2}\left\{\frac{\lambda L}{6}-\frac{1}{4}+\frac{1}{4 \lambda L}-\frac{1}{8 \lambda^{2} L^{2}}[1-\exp (-2 \lambda L)]\right\}
$$

Here, $L$ and $\lambda^{-1}$ are the contour length and the stiffness parameter, which is same as the Kuhn segment length (or twice the persistence length) in the conventional wormlike chain model. The former parameter is related to the molar mass $M$ by $L=M / M_{\mathrm{L}}$, with $M_{\mathrm{L}}$ representing the molar mass per unit contour length. Assuming the literature $M_{\mathrm{L}}$ value of $390 \mathrm{~nm}^{-1} \mathrm{~g} \mathrm{~mol}^{-1}$ for $\mathrm{PS},{ }^{35} \lambda^{-1}$ can be estimated using the least-squares method at each temperature, and then $C_{\infty}$ can be estimated by $C_{\infty}=L / \lambda n b^{2}=M_{0} / 2 \lambda M_{\mathrm{L}} b^{2}$, where $M_{0}$ represents the molar mass of the monomer, leading to the assumption that $M_{\mathrm{L}}$ does not result in a significant error of $C_{\infty}$. In actuality, if we assume a $10 \%$ larger (or smaller) $M_{\mathrm{L}}$, the resulting $C_{\infty}$ is at most $1 \%$ larger (or smaller) than the original value. The helical wormlike chain $^{3}$ is a better model for PS, ${ }^{36}$ but the differences between these two models may be negligible for the resulting $C_{\infty}$ determined from the current data because this difference is greater at a lower range of molar mass. Indeed, the $6<S^{2}>_{0} / n b^{2}$ values for PS22K and PS39K are close to the obtained $C_{\infty}$, that is, they are only $\sim 5 \%$ and $\sim 3 \%$ smaller than the $C_{\infty}$ values, respectively. Furthermore, $P(q)$ calculated in terms of the touched bead wormlike chain ${ }^{37,38}$ model reproduces the experimental data in MEK almost quantitatively, as shown in Figure 5, in which the following parameters were used: $M_{\mathrm{L}}=390$ $\mathrm{nm}^{-1} \mathrm{~g} \mathrm{~mol}^{-1}, \lambda^{-1}=1.9 \mathrm{~nm}$ and $d_{\mathrm{B}}=1.5 \mathrm{~nm}$. The latter two parameters can be obtained from the curve fitting procedure assuming that $M_{\mathrm{L}}=390 \mathrm{~nm}^{-1} \mathrm{~g} \mathrm{~mol}^{-1}$. The obtained value of $\lambda^{-1}$ 

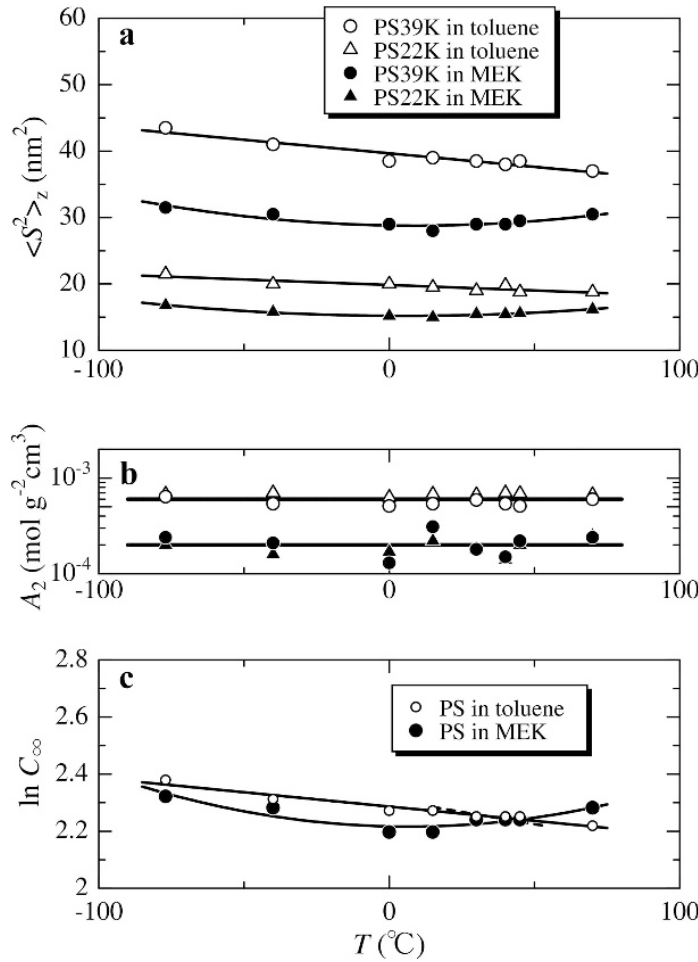

Figure 4 Temperature dependence of (a) the $z$-average mean-square radius of gyration $\left\langle S^{2}\right\rangle_{z}$ and (b) the second virial coefficient $A_{2}$ for PS39K (circles) and PS22K (triangles) in toluene (unfilled symbols) and in 2-butanone (MEK, filled symbols). (c) Temperature dependence of the natural logarithms of the characteristic ratio $C_{\infty}$ for PS in toluene (unfilled circles) and in MEK (filled circles). The broken line has the slope of $-1.7 \times 10^{-3} \mathrm{~K}^{-1}$ determined by Osa et al. ${ }^{6}$ for polystyrene in toluene.

may be overestimated $(\sim 6 \%)$ due to the intramolecular excludedvolume effect, and indeed $C_{\infty}$ is calculated to be 10.7 based on these parameters.

The resulting $C_{\infty}$ data are plotted against temperature in Figure 4c, and the experimental results are summarized in Table 2 . These values are fairly close to those in $\Theta$ solvents, that is, 10.6 in cyclohexane and 10.1 in trans-decalin calculated from $\left\langle S^{2}\right\rangle_{\mathrm{z}}$ versus $M_{\mathrm{w}}$ relationships for high molar mass PS. ${ }^{39-42}$ The slightly smaller $C_{\infty}$ values in toluene and MEK might be due to the narrower polydispersity of the current PS samples compared with those in the literature. The data points in toluene monotonically decrease with increasing temperature, and the obtained slope of $\mathrm{d} \ln C_{\infty} / \mathrm{d} T=-1.0 \times 10^{-3} \mathrm{~K}^{-1}$ is slightly larger than that estimated by Osa et al. ${ }^{6}$ (dashed line in Figure $4 \mathrm{c} \ln C_{\infty} /$ $\mathrm{d} T=-1.7 \times 10^{-3} \mathrm{~K}^{-1}$ ) in the same solvent system, and substantially the same as those determined in multiple $\Theta$ solvents by Mays et al. ${ }^{5}$

In the framework of the wormlike chain model, $\lambda^{-1}$ can be defined as the ratio of the bending force constant of the wormlike chain to $k_{\mathrm{B}} T$, where $k_{\mathrm{B}}$ is the Boltzmann constant. Therefore, $\mathrm{d} \ln C_{\infty} / \mathrm{d} T$ is written as

$$
\frac{\mathrm{d} \ln C_{\infty}}{\mathrm{d} T}=\frac{\mathrm{d} \ln \lambda^{-1}}{\mathrm{~d} T}=-\frac{1}{T}
$$

Thus, $\mathrm{d} \ln C_{\infty} / \mathrm{d} T$ is calculated to be $-3.66 \times 10^{-3} \mathrm{~K}^{-1}$ at $0^{\circ} \mathrm{C}$. This is on the same order as the experimentally determined value. In terms of the helical wormlike chain model, a similar value was obtained at $300 \mathrm{~K}$, that is, $\mathrm{d} \ln C_{\infty} / \mathrm{d} T=-3.21 \times 10^{-3} \mathrm{~K}^{-1} .{ }^{6}$ In contrast, $C_{\infty}$ in MEK exhibits a minimum $\sim 10^{\circ} \mathrm{C}$, suggesting that (helical) wormlike

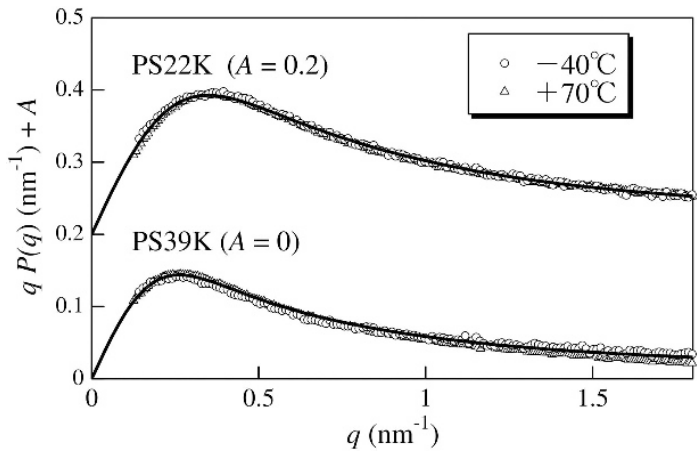

Figure 5 Holtzer plots for PS22K and PS39K in MEK at $-40{ }^{\circ} \mathrm{C}$ (circles) and $70^{\circ} \mathrm{C}$ (triangles). The solid line represents theoretical values for the touched bead wormlike chain model with $M_{\mathrm{L}}=390 \mathrm{~nm}^{-1} \mathrm{~g} \mathrm{~mol}^{-1}$, $\lambda^{-1}=1.9 \mathrm{~nm}$ and $d_{\mathrm{B}}=1.5 \mathrm{~nm}$. The ordinate values are shifted by $A$ for clarity.

Table 2 Characteristic ratio $C_{\infty}$ for PS in toluene and MEK

\begin{tabular}{lrr}
\hline & \multicolumn{2}{c}{$C_{\infty}$} \\
\cline { 2 - 3 }$T(C)$ & In toluene & In MEK \\
\hline-77 & 10.8 & 10.2 \\
-40 & 10.1 & 9.8 \\
0 & 9.7 & 9.0 \\
15 & 9.7 & 9.0 \\
30 & 9.5 & 9.4 \\
40 & 9.5 & 9.4 \\
45 & 9.5 & 9.4 \\
70 & 9.2 & 9.8 \\
\hline
\end{tabular}

or RIS parameters should depend on the temperature, at least in MEK. According to Munk et al., ${ }^{43}$ specific interactions between the phenyl ring of PS and the carbonyl group of ethyl acetate reduce the chain dimensions of PS. Furthermore, Mays et al. ${ }^{5}$ reported that the $C_{\infty}$ in chloroalkanes and diesters are unmistakably smaller than those in cyclohexanes at the same temperature. The positive $\mathrm{d} \ln C_{\infty} / \mathrm{d} T$ is thus most likely because the solvation state of PS in MEK depends significantly on temperature in the high temperature range. However, $\mathrm{d} \ln C_{\infty} / \mathrm{d} T$ in the lower temperature range becomes similar to that for PS in toluene, most likely because this temperature-dependent solvation behavior is not significant at lower temperatures.

\section{CONCLUSIONS}

In this study, we successfully obtained the radii of gyration for cATPC and polystyrene (PS) over a wide range of temperature from $-77^{\circ} \mathrm{C}$ to $70^{\circ} \mathrm{C}$. Whereas the radii of gyration for a rigid ring polymer (cATPC) do not change significantly, those for PS in toluene increase monotonically as the temperature is decreased, and furthermore the temperature coefficient $\mathrm{d} \ln C_{\infty} / \mathrm{d} T$ of PS in MEK changes from negative to positive as temperature is increased. This change is most likely due to temperature-dependent polymer-solvent interactions.

\section{ACKNOWLEDGEMENTS}

The synchrotron radiation experiments were performed at the BL40B2 in SPring-8 with the approval of the Japan Synchrotron Radiation Research Institute (JASRI) (Proposal Nos. 2012A1059, 2012B1050 and 2013A1046) and 
at the BL-10C in KEK-PF under the approval of the Photon Factory Program Advisory Committee (No. 2011G557). We thank Dr Noboru Ohta (SPring-8) for his help in setting up the SAXS apparatus in SPring-8, Ms Xin Yue Jiang (Osaka University) for performing preliminary SAXS measurements, and Professor Takahiro Sato (Osaka University) for fruitful discussion. This work was supported by JSPS KAKENHI Grant Numbers 23750128 and 25410130.

1 Flory, P. J. Statistical mechanics of chain molecule. (Interscience (1969).

2 Kratky, O. \& Porod, G. Rontgenuntersuchung geloster fadenmolekule. Recl. Trav. Chim. Pays-Bas. 68, 1106-1122 (1949).

3 Yamakawa, H. Helicimke chains in polymer solutions (Springer, 1997).

4 Yamakawa, H. A new framework of polymer solution science. The helical wormlike chain. Polym. J. 31, 109-119 (1999).

5 Mays, J. W., Hadjichristidis, N. \& Fetters, L. J. Solvent and temperature influences on polystyrene unperturbed dimensions. Macromolecules 18, 2231-2236 (1985).

6 Osa, M., Kanda, H., Yoshizaki, T. \& Yamakawa, H. Temperature coefficients of unperturbed chain dimensions for polystyrene and poly $(\alpha$-methylstyrene). Polym. J. 39, 423-427 (2007).

7 Mays, J. W., Hadjichristidis, N., Graessley, W. W. \& Fetters, L. J. Temperature dependence of unperturbed dimensions for stereoirregular 1,4-polybutadiene and poly( $\alpha$-methylstyrene). J. Polym. Sci., Part B: Polym. Phys 24, 2553-2564 (1986).

8 Mays, J. W., Nan, S. Y., Yunan, W., Li, J. \& Hadjichristidis, N. Temperature-dependence of chain dimensions for highly syndiotactic poly(methyl methacrylate). Macromolecules 24, 4469-4471 (1991).

9 Hong, F., Lu, Y. J., Li, J. F., Shi, W. J., Zhang, G. Z. \& Wu, C. Revisiting of dimensional scaling of linear chains in dilute solutions. Polymer. (Guildf). 51, 1413-1417 (2010).

10 Itou, T., Chikiri, H., Teramoto, A. \& Aharoni, S. M. Wormlike chain parameters of poly(hexyl isocyanate) in dilute-solution. Polym. J. 20, 143-151 (1988).

11 Terao, K., Terao, Y., Teramoto, A., Nakamura, N., Fujiki, M. \& Sato, T. Temperature and solvent dependence of stiffness of poly\{n-hexyl-[(S)-3-methylpentyl]silylene\} in dilute solutions. Macromolecules 34, 4519-4525 (2001).

12 Teramoto, A., Terao, K., Terao, Y., Nakamura, N., Sato, T. \& Fujiki, M. Interplay of the main chain, chiral side chains, and solvent in conformational transitions: $\operatorname{Poly}\{(R)-3,7-$ dimethyloctyl-(S)-3-methylpentyl silylene\}. J. Am. Chem. Soc. 123, 12303-12310 (2001).

13 Wu, L., Sato, T., Tang, H.-Z. \& Fujiki, M. Conformation of a polyfluorene derivative in solution. Macromolecules 37, 6183-6188 (2004).

14 Yanai, H. \& Sato, T. Local conformation of the cellulosic chain in solution. Polym. J. 38, 226-233 (2006).

15 Izumi, Y., Katano, S., Funahashi, S., Furusaka, M. \& Arai, M. Conformation of atactic polystyrene in carbon disulfide observed at a low temperature. Physica B: Condens Matter 180-181 (Part 1), 539-541 (1992).

16 Izumi, Y., Katano, S., Funahashi, S., Furusaka, M. \& Arai, M. Structural study on the sol-gel transition of atactic polystyrene in carbon disulfide. Physica B: Condens Matter 180-181 (Part 1), 545-548 (1992).

17 Izumi, Y. Structure and mechanism of atactic polystyrene physical gel. Kobunshi Ronbunshu 55, 749-759 (1998).

18 Tsunashima, Y., Ikuno, M., Onodera, G. \& Horii, F. Low-temperature dynamic light scattering. I. Structural reorganization and physical gel formation in cellulose triacetate/methyl acetate dilute solution at $-99-45^{\circ} \mathrm{C}$. Biopolymers $82,222-233$ (2006).

19 Nakamura, Y., Akashi, K., Norisuye, T., Teramoto, A. \& Sato, M. Small-angle x-ray scattering with imaging plate application to dilute polymer solutions. Polym. Bull. $\mathbf{3 8}$, 469-476 (1997).
20 Terao, K., Asano, N., Kitamura, S. \& Sato, T. Rigid cyclic polymer in solution: Cycloamylose tris(phenylcarbamate) in 1,4-dioxane and 2-ethoxyethanol. ACS Macro Lett 1, 1291-1294 (2012).

21 Miyaki, Y. \& Fujita, H. Excluded-volume effects in dilute polymer solutions. 11. Tests of the two-parameter theory for radius of gyration and intrinsic viscosity. Macromolecules 14, 742-746 (1981).

22 Okumoto, M., Terao, K., Nakamura, Y., Norisuye, T. \& Teramoto, A. Excluded-volume effects in star polymer solutions: Four-arm star polystyrene in cyclohexane near the theta temperature. Macromolecules 30, 7493-7499 (1997).

23 Berry, G. C. Thermodynamic and conformational properties of polystyrene.I. Lightscattering studies on dilute solutions of linear polystyrenes. J. Chem. Phys. 44, 4550-4564 (1966).

24 Terao, K. \& Mays, J. W. On-line measurement of molecular weight and radius of gyration of polystyrene in a good solvent and in a theta solvent measured with a twoangle light scattering detector. Eur. Polym. J 40, 1623-1627 (2004).

25 Terao, K., Shigeuchi, K., Oyamada, K., Kitamura, S. \& Sato, T. Solution properties of a cyclic chain having tunable chain stiffness: Cyclic amylose tris( $n$-butylcarbamate) in $\Theta$ and good solvents. Macromolecules 46, 5355-5362 (2013).

26 Abe, F., Einaga, Y., Yoshizaki, T. \& Yamakawa, H. Excluded-volume effects on the mean-square radius of gyration of oligo- and polystyrenes in dilute solutions. Macromolecules 26, 1884-1890 (1993).

27 Nakata, M. Excluded volume effects in dilute solutions of linear polystyrene. Makromol. Chem. 149, 99-115 (1971).

28 Einaga, Y., Abe, F. \& Yamakawa, H. Second virial coefficients of oligo- and polystyrenes. Effects of chain ends. Macromolecules 26, 6243-6250 (1993).

29 Akcasu, A. Z. \& Han, C. C. Molecular weight and temperature dependence of polymer dimensions in solution. Macromolecules 12, 276-280 (1979).

30 Yamakawa, H. \& Stockmayer, W. H. Statistical mechanics of wormlike chains. II. Excluded volume effects. J. Chem. Phys. 57, 2843-2854 (1972).

31 Shimada, J. \& Yamakawa, H. Statistical-mechanics of helical worm-like chains.25. Excluded-volume effects. J. Chem. Phys. 85, 591-600 (1986).

32 Domb, C. \& Barrett, A. J. Universality approach to expansion factor of a polymer-chain. Polymer. (Guildf). 17, 179-184 (1976).

33 Barrett, A. J. Intrinsic viscosity and friction coefficients for an excluded volume polymer in the kirkwood approximations. Macromolecules 17, 1566-1572 (1984).

34 Benoit, H. \& Doty, P. Light scattering from non-gaussian chains. J. Phys. Chem. 57, 958-963 (1953).

35 Norisuye, T. \& Fujita, H. Excluded-volume effects in dilute polymer solutions. Xiii. Effects of chain stiffness. Polym. J. 14, 143-147 (1982).

36 Konishi, T., Yoshizaki, T., Saito, T., Einaga, Y. \& Yamakawa, H. Mean-square radius of gyration of oligostyrenes and polystyrenes in dilute-solutions. Macromolecules 23, 290-297 (1990).

37 Nakamura, Y. \& Norisuye, T. Scattering function for wormlike chains with finite thickness. J. Polym. Sci., Part. B: Polym. Phys. 42, 1398-1407 (2004).

38 Nakamura, Y. \& Norisuye, T. In Soft-matter characterization Pecora, R. \& Borsali, $R$. (eds. Vol. 1, 236-286 (Springer, 2008).

39 Miyaki, Y., Einaga, Y. \& Fujita, H. Excluded-volume effects in dilute polymersolutions.7. Very high molecular-weight polystyrene in benzene and cyclohexane. Macromolecules 11, 1180-1186 (1978).

40 Fukuda, M., Fukutomi, M., Kato, Y. \& Hashimot., T. Solution properties of high molecular-weight polystyrene. J. Polym. Sci., Part. B: Polym. Phys. 12, 871-890 (1974).

41 Inagaki, H., Suzuki, H., Fujii, M. \& Matsuo, T. Note on experimental tests of theories for the excluded volume effect in polymer coils. J. Phys. Chem. 70, 1718-1726 (1966).

42 Fetters, L. J., Hadjichristidis, N., Lindner, J. S. \& Mays, J. W. Molecular-weight dependence of hydrodynamic and thermodynamic properties for well-defined linearpolymers in solution. J. Phys. Chem. Ref. Data 23, 619-640 (1994).

43 Munk, P., Abijaoude, M. T. \& Halbrook, M. E. Intrinsic viscosity of polystyrene in mixed solvents. J. Polym. Sci., Polym. Phys. Ed. 16, 105-115 (1978). 